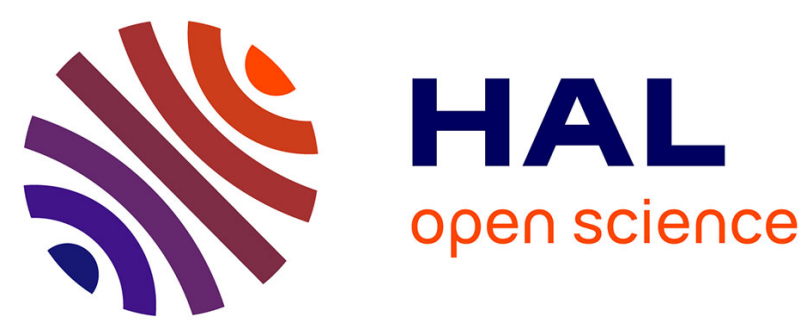

\title{
Do parasites adopt different strategies in different intermediate hosts? Host size, not host species, influences Coitocaecum parvum (Trematoda) life history strategy, size and egg production.
}

\author{
R Ruiz Daniels, S. Beltran, R. Poulin, C. Lagrue
}

\section{To cite this version:}

R Ruiz Daniels, S. Beltran, R. Poulin, C. Lagrue. Do parasites adopt different strategies in different intermediate hosts? Host size, not host species, influences Coitocaecum parvum (Trematoda) life history strategy, size and egg production.. Parasitology, 2012, pp.1-9. 10.1017/S0031182012001564 . hal-00777394

\section{HAL Id: hal-00777394 \\ https://hal.science/hal-00777394}

Submitted on 17 Jan 2013

HAL is a multi-disciplinary open access archive for the deposit and dissemination of scientific research documents, whether they are published or not. The documents may come from teaching and research institutions in France or abroad, or from public or private research centers.
L'archive ouverte pluridisciplinaire HAL, est destinée au dépôt et à la diffusion de documents scientifiques de niveau recherche, publiés ou non, émanant des établissements d'enseignement et de recherche français ou étrangers, des laboratoires publics ou privés. 


\title{
Parasitology
}

http://journals.cambridge.org/PAR

Additional services for Parasitology:

Email alerts: $\underline{\text { Click here }}$

Subscriptions: $\underline{\text { Click here }}$

Commercial reprints: Click here

Terms of use : $\underline{\text { Click here }}$

\section{Do parasites adopt different strategies in different intermediate hosts? Host size, not host species, influences Coitocaecum parvum (Trematoda) life history strategy, size and egg production}

\author{
R. RUIZ DANIELS, S. BELTRAN, R. POULIN and C. LAGRUE
}

Parasitology / FirstView Article / October 2012, pp 1 - 9

DOI: 10.1017/S0031182012001564, Published online:

Link to this article: http://journals.cambridge.org/abstract_S0031182012001564

How to cite this article:

R. RUIZ DANIELS, S. BELTRAN, R. POULIN and C. LAGRUE Do parasites adopt different strategies in different intermediate hosts? Host size, not host species, influences Coitocaecum parvum (Trematoda) life history strategy, size and egg production. Parasitology, Available on CJO doi:10.1017/S0031182012001564

Request Permissions : $\underline{\text { Click here }}$ 


\title{
Do parasites adopt different strategies in different intermediate hosts? Host size, not host species, influences Coitocaecum parvum (Trematoda) life history strategy, size and egg production
}

\author{
R. RUIZ DANIELS ${ }^{1,2}$, S. BELTRAN ${ }^{1}$, R. POULIN ${ }^{2}$ and C. LAGRUE ${ }^{2}$ * \\ ${ }^{1}$ Université de Poitiers, UMR CNRS 7267, Laboratoire EBI Ecologie Eं Biologie des Interactions, \\ Equipe Ecologie Evolution Symbiose, Poitiers, France \\ ${ }^{2}$ University of Otago, Department of Zoology, Dunedin, New Zealand
}

(Received 2 Fuly 2012; revised 24 Fuly 2012; accepted 21 August 2012)

SUMMARY

Host exploitation induces host defence responses and competition between parasites, resulting in individual parasites facing highly variable environments. Alternative life strategies may thus be expressed in context-dependent ways, depending on which host species is used and intra-host competition between parasites. Coitocaecum parvum (Trematode) can use facultative progenesis in amphipod intermediate hosts, Paracalliope fluviatilis, to abbreviate its life cycle in response to such environmental factors. Coitocaecum parvum also uses another amphipod host, Paracorophium excavatum, a species widely different in size and ecology from $P$. fluviatilis. In this study, parasite infection levels and strategies in the two amphipod species were compared to determine whether the adoption of progenesis by $C$. parvum varied between these two hosts. Potential differences in size and/or egg production between $C$. parvum individuals according to amphipod host species were also investigated. Results show that $C$. parvum life strategy was not influenced by host species. In contrast, host size significantly affected C. parvum strategy, size and egg production. Since intra-host interactions between co-infecting parasites also influenced $C$.parvum strategy, size and fecundity, it is highly likely that within-host resource limitations affect C. parvum life strategy and overall fitness regardless of host species.

Key words: life cycle abbreviation, intermediate hosts, Coitocaecum parvum, Paracalliope fluviatilis, Paracorophium excavatum.

\section{INTRODUCTION}

Phenotypic plasticity is often seen as an adaptive strategy in highly variable environments (Anurag, 2001). Host exploitation by parasites generally results in rapid evolutionary responses of hosts for defence purposes, resulting in a situation where parasites face a constantly changing environment and have to co-evolve with their hosts (Van Valen, 1974). Furthermore, the fitness of a parasite completely depends upon host-parasite interactions; infection and reproduction rates in a particular host-determining parasite success (Paterson and Piertney, 2011). Parasite phenotypic plasticity and alternative growth strategies should thus be expressed in precise context-dependent ways, depending on the parasite's environment/host (Thomas et al. $2002 a$; Parker et al . 2003).

The environment of a parasite is often not restricted to a single host since multiple species, parasites and/or hosts, are frequently encountered in a parasite life cycle (Fredensborg and Poulin,

* Corresponding author: Department of Zoology, University of Otago, 340 Great King Street, PO Box 56, Dunedin 9054, New Zealand, Tel: + 6434797986 . Fax: +643479 7584. E-mail: clement.lagrue@gmail.com
2005; Gower and Webster, 2005; Rauch et al. 2005). This is especially true for trematodes, their complex life cycles involving up to 4 widely different hosts and countless potential intra- and interspecific parasite competitors (Poulin, 2007). Although in the majority of trematodes a three-host life cycle is maintained, several species have lost a host from their cycle (Poulin and Cribb, 2002). This life-cycle abbreviation is often realized by dropping the definitive host, maturing and reproducing in the second intermediate host through progenesis and self-fertilization. In some species, life-cycle abbreviation remains facultative and both strategies are observed concurrently in parasite populations (Poulin and Cribb, 2002).

For example, the digenean trematode Coitocaecum parvum is able to adaptively adopt progenesis or the normal 3-host life cycle in response to different environmental factors (MacFarlane, 1939; Holton, 1984a,b; Lagrue and Poulin, 2007, 2008a). Adult $C$. parvum colonize the digestive tract of fish definitive hosts where they sexually reproduce. Eggs are released with fish feces and hatch into freeswimming miracidiae. After entering the first intermediate host, the snail Potamopyrgus antipodarum, they develop into cercariae-producing sporocysts. 
Cercariae leave the snail and must infect an amphipod second intermediate host where they encyst as metacercariae. The parasite can then adopt one of two alternative life strategies; either wait for a fish definitive host to consume the infected amphipod host or undergo progenesis while still inside the amphipod intermediate host and reproduce by selfing (Poulin and Cribb, 2002; Lefèbvre and Poulin, 2005). Progenetic individuals produce viable eggs released into the environment upon the death of the amphipod host. A previous study showed no evidence for heritability of progenesis or negative effects of selfing on offspring fitness (Lagrue and Poulin, $2009 a$ ). However, many factors influence adoption of the abbreviated life cycle by individual $C$. parvum. For example, progenesis rate increases when fish definitive hosts are absent from the environment (Lagrue and Poulin, 2007). Time spent in the amphipod host also increases the likelihood of progenesis adoption (Lagrue and Poulin, 2009b). Finally, co-infecting parasites and intra-host competition in the second intermediate host (the amphipod Paracalliope fluviatilis) strongly affect the adoption of progenesis in C. parvum (Lagrue and Poulin, 2008a; Lagrue et al. 2009).

Although $C$. parvum uses 2 different amphipod species as intermediate hosts, how its life-history strategy (abbreviated or normal 3-host cycle) may differ between these two hosts remains unknown. The two amphipod species often co-exist in the field despite profound ecological differences. While Paracalliope fluviatilis is demersal and freeswimming, Paracorophium excavatum is a purely benthic, sedentary, burrow-dwelling amphipod; this may increase its exposure to the non-swimming cercariae of C. parvum (Holton, 1984a). Paracorophium excavatum is also larger, may provide more resources to trematode parasites and thus affect the adoption of progenesis by $C$. parvum and/or egg production in progenetic individuals. Most studies have only considered $P$. fluviatilis as $C$. parvum intermediate host even though $P$. excavatum was early documented as a potential host in which progenesis occurred (Holton, 1984a; Luque et al. 2007). However, potential differences in progenesis rates and egg production between $C$. parvum individuals infecting co-existing $P$. fluviatilis and P. excavatum are still unknown.

While intra-host (intra- and interspecific) competition among parasites is known to affect both life strategy and egg production in $C$. parvum, these effects have been studied only in $P$. fluviatilis (Lagrue and Poulin, 2008a). Intraspecific competition between co-infecting $C$. parvum individuals strongly affects progenesis rates and decreases egg production in P. fluviatilis, the smaller of the two amphipod host species (Lagrue and Poulin, 2008a). It is possible that such effects are dampened by the larger size and higher available resources of $P$. excavatum hosts.
Similarly, Microphallus sp. is known to infect both amphipods species (Luque et al. 2007). It is also capable of manipulating amphipod host behaviour to enhance its transmission to bird definitive hosts (Hansen and Poulin, 2005; Coats et al. 2010). Because C. parvum and Microphallus sp. do not share definitive hosts, conflicting interests over transmission routes and/or developmental strategy are likely to arise (Brown, 1999; Thomas et al. 2002b; Poulin et al. 2003). Coitocaecum parvum might thus benefit from adopting progenesis in the presence of Microphallus sp.; its transmission probabilities being likely reduced by Microphallus sp. host manipulation. Microphallus sp. prevalence and abundance are also much higher in $P$. excavatum than $P$. fuviatilis (Luque et al. 2007). Furthermore, P. excavatum is host to a large fish nematode (Hedruris spinigera) while P. fluviatilis is not (Luque et al. 2007; Lagrue and Poulin, 2008a,b). Metacercariae of $C$. parvum infecting $P$. excavatum are consequently more likely to compete with other parasites than conspecifics in $P$. fluviatilis. Natural prevalence and/or abundance variations in parasitic infections between $P$. excavatum and $P$. fluviatilis may consequently influence progenesis adoption in $C$. parvum in its two intermediate host species.

In this study, we examined parasite prevalences and abundances in the two amphipod host species and gave particular attention to the frequency of progenesis in $C$. parvum infecting $P$. excavatum and $P$. fluviatilis to detect possible species-specific intermediate host-induced effects on the parasite strategy. For C. parvum individuals that adopted progenesis, we determined whether parasite size and/or egg production was higher in $P$. excavatum than in the smaller P. fluviatilis. Finally, we examined potential effects of interactions with co-infecting parasites on size and egg production of progenetic C. parvum.

\section{MATERIALS AND METHODS}

\section{Study site and animal sampling}

Naturally infected Paracalliope fluviatilis and Paracorophium excavatum amphipods were collected in Lake Waihola $\left(46^{\circ} 01^{\prime} \mathrm{S}, 170^{\circ} 05^{\prime} \mathrm{E}\right)$, South Island, New Zealand, using dip nets (500 $\mu$ m nylon mesh). All amphipods were collected during February and April 2012 and both species were collected at the same time and location to avoid potential spatial or temporal effects on parasite prevalences and/or abundances. Paracorophium excavatum were captured by dredging the fine surficial sediment where this species burrows. The retained sediment with associated organisms was placed in sorting trays from which $P$. excavatum individuals were collected (Schnabel et al. 2000). Paracalliope fluviatilis were collected from the same area by dragging dip nets in patches of macrophytes (Elodea canadensis). 
Amphipods were separated from macrophytes using a $5 \mathrm{~mm}$ mesh sieve and collected in sorting trays. All amphipods were kept alive in plastic containers filled with local water and brought back to the laboratory for later dissection. Amphipods were dissected within 3 days of capture.

\section{Parasite prevalences and abundances, and}

Coitocaecum parvum strategy, size and egg production

Amphipods were killed in $70 \%$ ethanol and rinsed with distilled water to allow for easy manipulation (measurement and dissection) without affecting data collection on parasites (Lefèbvre and Poulin, 2005). Before dissection, amphipods were identified (species) and measured (total body length) to the closest $0 \cdot 1 \mathrm{~mm}$ under a binocular microscope $(\times 20$ magnification) as host size can influence parasite prevalence and abundance in naturally infected amphipods (Lagrue and Poulin, 2008b). For each amphipod, the species (C. parvum, Microphallus sp. and/or $H$. spinigera) and number of parasites were recorded to determine parasite prevalences (proportion of infected hosts) and abundances (number of parasites per host). Metacercariae of C. parvum were also classified as either normal (non-egg producing) or progenetic (egg producing) according to the presence of eggs in the cyst or still in utero. Each metacercaria was measured (total length) and its eggs counted.

\section{Statistical analysis}

Potential differences in parasite prevalences and/or proportion of progenetic $C$. parvum between the two amphipod species were tested in a pair-wise manner using Fisher's exact tests. Effects of intermediate host species ( $P$. fluviatilis and $P$. excavatum) on specific parasite abundances (C. parvum, Microphallus sp. and $H$. spinigera) and possible differences in host size between the two amphipod species and between infected and uninfected hosts were examined using non-parametric tests (Mann-Whitney U test), as data did not follow normal distributions. Potential relationships between host size, parasite abundance, and $C$. parvum size and egg production were also tested using linear regressions. Non-parametric tests and linear regressions described above were performed using STATISTICA Software 6.0 (StatSoft Inc., France).

General Linear Models (GLM) were used to test for the effects of multiple factors on the probability of $C$. parvum metacercariae adopting progenesis, and on the size and/or egg production of progenetic metacercariae. Factors potentially affecting the probability of progenesis in $C$. parvum and included in the models were host species, host size, number of coinfecting Microphallus sp., number of co-infecting non-egg producing $C$. parvum metacercariae and/or presence of the fish nematode $H$. spinigera. The dependent variable was treated in a binomial manner with $C$. parvum metacercariae coded either as 1 (progenetic/egg-producing) or 0 (non-egg producing). GLMs were also performed to determine the factors affecting the size and egg production of progenetic metacercariae. Host species, host size, number of co-infecting Microphallus sp., number of co-infecting non-egg producing $C$. parvum metacercariae and/or presence of $H$. spinigera were included as factors in those GLMs. The size of progenetic metacercariae was also included as a factor when egg production was the response variable. In GLMs testing for the factors affecting $C$. parvum egg production, only amphipod hosts containing eggproducing C. parvum were included. Log-transformation before analyses was used when necessary to normalize the data. All factors were initially included in the GLMs to determine the most appropriate model using the Akaike Information Criterion (AIC), with the model awarded the lowest AIC having the highest explanatory power for the observed data. Only factors remaining in the best models are presented in the GLM result tables. In all models, effect size was determined using t-values and degrees of freedom. GLMs were performed using R Software 2.15.0 (R Development Core Team, 2011).

\section{RESULTS}

\section{Host species, host size and parasite prevalences} and abundances

Overall, 812 amphipods were measured and dissected, 219 P. excavatum and 593 P. fluviatilis. Parasite prevalences were significantly higher in $P$. excavatum than $P$. fluviatilis (Fisher's exact tests, $\chi^{2}=57 \cdot 64,47 \cdot 65$ and $224 \cdot 54$, all $P<0.0001$ for C. parvum, H. spinigera and Microphallus sp., respectively; see Table 1 for details). Similarly, parasite abundances were significantly higher in $P$. excavatum than $P$. fluviatilis (Mann-Whitney U test, $Z=8 \cdot 284,7 \cdot 056$ and $17 \cdot 396$, all $P<0 \cdot 0001$ for C. parvum, Microphallus sp. and $H$. spinigera respectively; Table 1 ).

Host size was significantly different between the two amphipod species (Mann-Whitney U test, $\mathrm{Z}=15.916, P<0 \cdot 0001) ; P$. excavatum being larger than P. fluviatilis (Table 2). Amphipod size was also different between infected and uninfected individuals. In $P$. excavatum, infected individuals were significantly larger than their uninfected conspecifics for the three parasites species (Mann-Whitney $\mathrm{U}$ test, $\mathrm{Z}=-3 \cdot 479,-2 \cdot 42$ and $-3 \cdot 046, P=0.0005,0 \cdot 016$ and 0.002 for C. parvum, Microphallus sp. and. $H$. spinigera, respectively; see Table 2 for details). The same trend was observed in P. fluviatilis with C. parvum and Microphallus sp. infected amphipods 
Table 1. Prevalences (proportion of infected amphipods) and abundances (mean number of parasites \pm s.E. per individual amphipod) for the three species of parasites (Coitocaecum parvum, Microphallus sp. and Hedruris spinigera) in the two amphipod host species (Paracorophium excavatum and Paracalliope fluviatilis) sampled in Lake Waihola

(When prevalence was 0 , parasite abundance could not be calculated and is shown as not available (na).)

\begin{tabular}{|c|c|c|c|c|}
\hline Host & P. fluviatilis & & P. excavatum & \\
\hline Parasite & Prevalence $(\%)$ & Abundance ( \pm s.E.) & Prevalence (\%) & Abundance ( \pm s.E.) \\
\hline C. parvum & $18 \cdot 2$ & $0 \cdot 30 \pm 0 \cdot 09$ & $44 \cdot 3$ & $1 \cdot 42 \pm 0 \cdot 25$ \\
\hline Microphallus sp. & $22 \cdot 8$ & $0 \cdot 46 \pm 0 \cdot 14$ & $80 \cdot 4$ & $8 \cdot 66 \pm 0 \cdot 96$ \\
\hline H. spinigera & $0 \cdot 0$ & na & $8 \cdot 2$ & $0 \cdot 08 \pm 0 \cdot 06$ \\
\hline
\end{tabular}

Table 2. Host size (mean amphipod body length in $\mathrm{mm} \pm$ S.E.) for the two amphipod species (Paracorophium excavatum and Paracalliope fluviatilis) sampled in Lake Waihola according to their infection status (infected or uninfected (i.e. uninf.))

(Data are shown for the three species of parasites, Coitocaecum parvum, Microphallus sp. and Hedruris spinigera. When parasite prevalence was 0 , mean infected host size is shown as not available (na).)

\begin{tabular}{|c|c|c|c|c|c|c|c|}
\hline \multicolumn{2}{|l|}{ Parasite } & \multicolumn{2}{|c|}{ C.parvum } & \multicolumn{2}{|c|}{ Microphallus sp. } & \multicolumn{2}{|c|}{ H. spinigera } \\
\hline Host size (mm \pm s.E. $)$ & Total & Infected & Uninf. & Infected & Uninf. & Infected & Uninf. \\
\hline P. excavatum & $4 \cdot 0 \pm 0 \cdot 1$ & $4 \cdot 2 \pm 0 \cdot 1$ & $3 \cdot 8 \pm 0 \cdot 1$ & $4 \cdot 1 \pm 0 \cdot 1$ & $3 \cdot 7 \pm 0 \cdot 1$ & $4 \cdot 6 \pm 0 \cdot 2$ & $3 \cdot 9 \pm 0 \cdot 1$ \\
\hline P. fluviatilis & $2 \cdot 8 \pm 0 \cdot 0$ & $3 \cdot 1 \pm 0 \cdot 1$ & $2 \cdot 7 \pm 0 \cdot 0$ & $2 \cdot 9 \pm 0 \cdot 1$ & $2 \cdot 8 \pm 0 \cdot 0$ & na & na \\
\hline
\end{tabular}

being significantly larger than uninfected individuals (Mann-Whitney $U$ test, $Z=-5 \cdot 393$ and $-3 \cdot 059$, $P<0 \cdot 0001$ and $P=0 \cdot 002$, respectively; Table 2); note that $H$. spinigera was never found infecting $P$. fluviatilis. There was also a significant effect of host size on parasite abundances (number of parasites per individual host). Larger P. excavatum individuals tended to be more heavily infected than their smaller conspecifics $(r=0.338,0.436$ and $0 \cdot 207, n=219$, $P<0.0001, P<0.0001$ and $P=0.002$ for $C$. parvum, Microphallus sp. and $H$. spinigera, respectively; Fig. 1). Again, similar trends were detected in $P$. fluviatilis; parasite abundances were significantly correlated to amphipod host size $(r=0.208$ and $0 \cdot 180, n=593$, both $P<0 \cdot 0001$ for $C$. parvum and Microphallus sp., respectively; Fig. 1).

Coitocaecum parvum strategy, size and egg production

A total of $488 C$. parvum metacercariae were recovered; 311 found in $P$. excavatum and 177 in P. fluviatilis. The proportion of progenetic metacercariae was not significantly different between the two host species $(12 \cdot 8 \%$ and $14 \cdot 7 \%$ for $P$. excavatum and $P$. fluviatilis, respectively; Fisher's exact test, $\left.\chi^{2}=0.32, P=0 \cdot 570\right)$. This is consistent with results from GLMs showing that only host size had a significant effect on $C$. parvum strategy (Table 3 ). Host species and the number of co-infecting nonprogenetic $C$. parvum were included in the model with the lowest AIC score although their effect size was small and not statistically significant (Table 3 ).
The presence of Microphallus sp. metacercariae had no detectable effect on $C$. parvum strategy.

Similarly, host species did not influence the size of progenetic metacercariae (Table 4). The only factor significantly influencing $C$. parvum size was the host size; larger amphipod hosts tending to harbour larger egg-producing $C$. parvum metacercariae, regardless of host species $(r=0.559, n=57, P<0 \cdot 0001$; Fig. 2). Again, host species had no effect on $C$. parvum egg production. The number of eggs produced by progenetic $C$. parvum was clearly influenced by the size of the metacercaria (Table 5); egg production increasing with $C$. parvum size, regardless of host species $(r=0 \cdot 826, n=57, P<0 \cdot 0001$; Fig. 3$)$. Intrahost interactions between parasite species seemed to play a major role on $C$. parvum egg production (Table 5). Furthermore, these effects are likely to be species-specific. Progenetic C. parvum egg production was clearly higher in the presence of Microphallus sp. (mean egg production \pm s.E. $=306 \cdot 9 \pm 50 \cdot 2$ and $151 \cdot 7 \pm 38 \cdot 4$ with and without co-infecting Microphallus sp., respectively; MannWhitney U test, $Z=-1.993, P=0.046)$. However, there was no significant effect of the presence of nonprogenetic $C$. parvum $(241.4 \pm 50 \cdot 4$ and $219.9 \pm 41.9$ with and without co-infecting non-progenetic C. parvum, respectively; Mann-Whitney $\mathrm{U}$ test, $Z=0 \cdot 176, P=0 \cdot 868)$, possibly because of a densitydependent effect, rather than just presence or absence (Table 5; Lagrue and Poulin, 2008a). Contrastingly, co-infection with $H$. spinigera significantly reduced $C$. parvum egg production in 

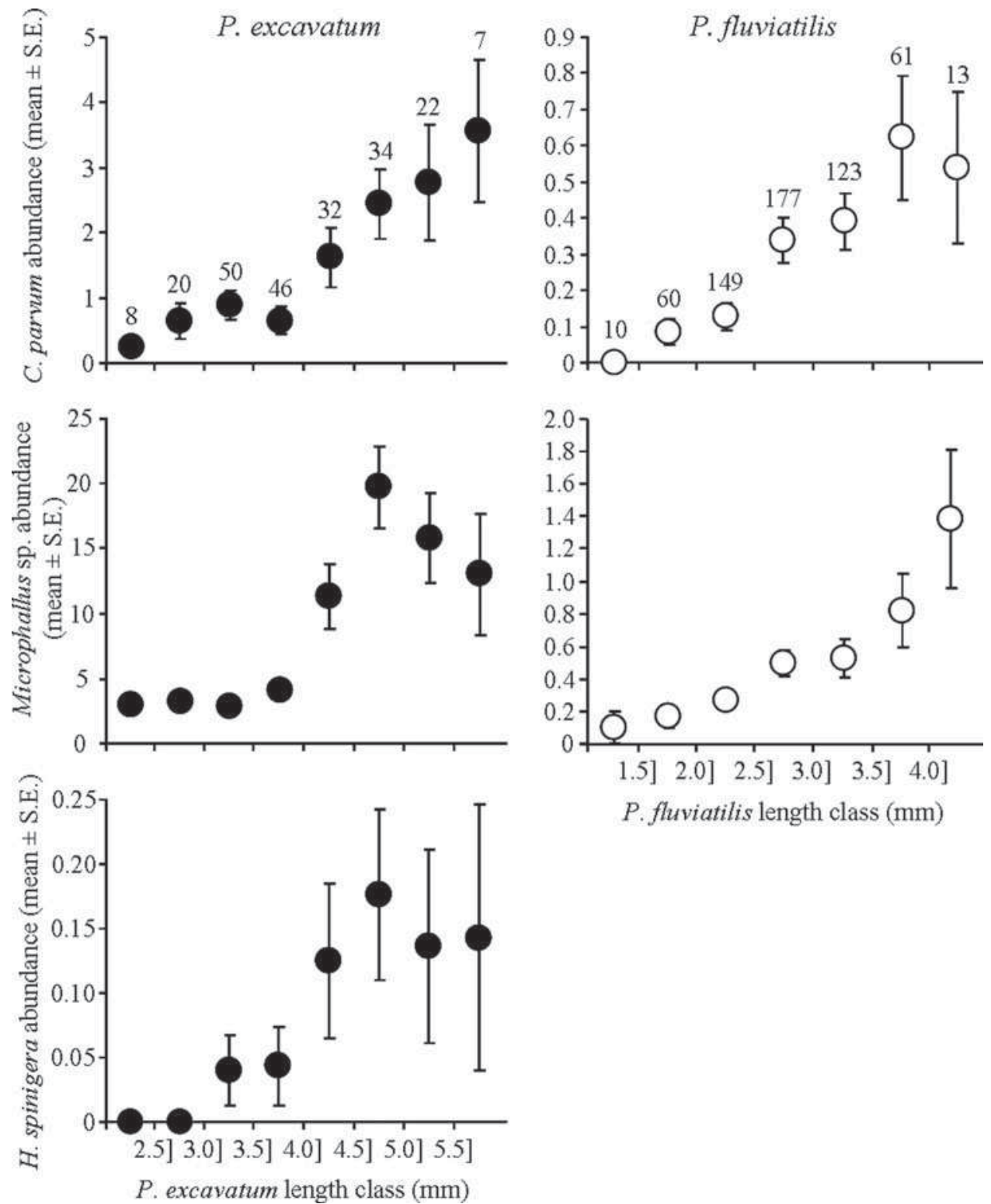

$P$. fluviatilis length class ( $\mathrm{mm}$ )

Fig. 1. Abundances (mean \pm s.E.) of Coitocaecum parvum (top graphs), Microphallus sp. (middle) and Hedruris spinigera (bottom graph) in relation to host size (amphipod length class) in Paracorophium excavatum (left graphs) and

Paracalliope fluviatilis (right). Sample size (i.e. number of amphipods) per host size class is indicated above each data point on the top graphs. Note that $P$. fluviatilis was never infected by $H$. spinigera.

P. excavatum $(61 \cdot 2 \pm 19 \cdot 1$ and $367 \cdot 2 \pm 54 \cdot 3$ with and without co-infecting $H$. spinigera, respectively; Mann-Whitney $U$ test, $\quad Z=2 \cdot 724, \quad P=0 \cdot 004)$; $P$. fluviatilis was not considered here since it was never infected by $H$. spinigera.

\section{DISCUSSION}

The main goal of the study was to explore potential factors influencing the frequency of progenesis in C. parvum metacercariae in their amphipod second intermediate hosts. In particular, we tested whether the parasite adjusted its life strategy to the species of amphipod host. Results show that host species per se did not influence $C$. parvum's strategy; the proportion of progenetic metacercariae was similar in
P. excavatum and P. fluviatilis, the two amphipod host species. Furthermore, intermediate host species per se had no effect on progenetic $C$. parvum size or egg production.

Overall, P. excavatum was more heavily infected than P. fluviatilis. Both prevalence and abundance of the three parasite species were higher in P. excavatum. Whether this difference was due to the larger size of this species compared to P. fluviatilis or different biological characteristics between the two amphipod species (benthic versus demersal and/or sedentary burrowing versus free-swimming, respectively) cannot be determined with certainty from our study. However, since larger individuals tend to be more heavily infected than smaller individuals in both amphipod species and P. excavatum is significantly 
Table 3. General Linear Model testing for the effects of host species (Paracorophium excavatum and Paracalliope fluviatilis), host size (total body length), number of co-infecting parasites (Microphallus sp. and/ or non-progenetic Coitocaecum parvum metacercariae) and presence of the nematode Hedruris spinigera on C. parvum life strategy (occurrence of progenetic individuals) in amphipod hosts

(Results shown originate from the model awarded the lowest AIC (Akaike Information Criterion) score. Significant $P$ values are indicated by *)

\begin{tabular}{lllrr}
\hline \hline Factors & Estimate & S.E. & $t$-value & $P$ \\
\hline Host species & $0 \cdot 562$ & $0 \cdot 404$ & $1 \cdot 390$ & $0 \cdot 165$ \\
Host size & $1 \cdot 348$ & $0 \cdot 217$ & $6 \cdot 221$ & $0 \cdot 049$ \\
Non-progenetic C. parvum & $0 \cdot 093$ & $0 \cdot 067$ & $1 \cdot 379$ & $0 \cdot 0001 *$ \\
\hline \hline
\end{tabular}

Table 4. General Linear Model testing for the effects of host species (Paracorophium excavatum and Paracalliope fluviatilis), host size (total body length), number of co-infecting parasites (Microphallus sp. and/ or non-progenetic Coitocaecum parvum metacercariae) and presence of the nematode Hedruris spinigera on the size of progenetic C. parvum metacercariae (body length)

(Results shown originate from the model awarded the lowest AIC (Akaike Information Criterion) score. Significant $P$ values are indicated by ${ }^{*}$.)

\begin{tabular}{lcllll}
\hline \hline Factors & Estimate & s.E. & $t$-value & $P$ & Effect size \\
\hline Host size & $0 \cdot 151$ & 0.044 & $3 \cdot 409$ & $0 \cdot 001^{*}$ & $0 \cdot 415$ \\
Microphallus sp. & -0.003 & 0.003 & $1 \cdot 122$ & $0 \cdot 267$ & $0 \cdot 148$ \\
\hline \hline
\end{tabular}

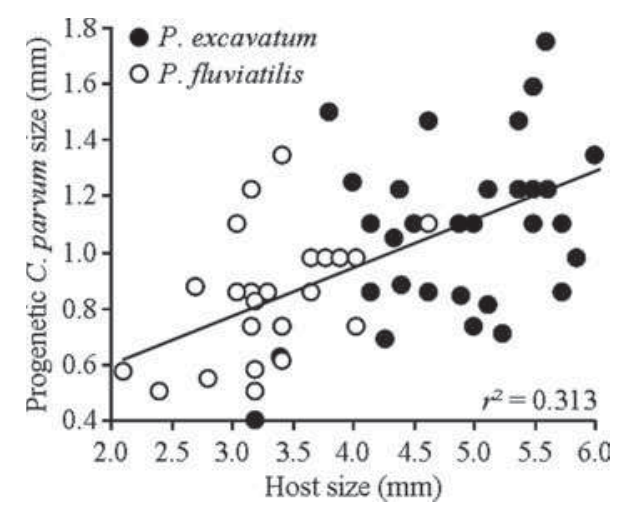

Fig. 2. Relationship between amphipod host size (body length in $\mathrm{mm}$ ) and the size of progenetic Coitocaecum parvum metacercariae (body length in $\mathrm{mm}$ ) in the two amphipod species, Paracorophium excavatum and Paracalliope fluviatilis. Line of best fit and coefficient of determination are shown on the figure.

larger than $P$. fluviatilis, it is likely that host size plays a significant role in parasite infection levels. Nevertheless, C. parvum cercariae cannot swim and instead crawl on the substrate to find a suitable intermediate host while $H$. spinigera is transmitted through the ingestion of the parasite eggs by amphipod hosts. It is thus possible that the benthic and detritivore life style of $P$. excavatum leads to higher exposure to infections in this species compared to $P$. fluviatilis. Information on Microphallus sp. transmission mode is lacking and interpretation of our results is difficult but similar trends are plausible.
Larger host size may also be linked to higher levels of within-host resources availability to parasites allowing for higher parasite abundance, growth and/or egg production (Saad-Fares and Combes, 1992; Grutter and Poulin, 1998; Johnson et al. 2005). Although host species per se did not affect the likelihood of $C$. parvum adopting progenesis, our results show that host size and thus possibly withinhost space/resources significantly affected parasite abundances and $C$. parvum strategy, size and egg production. The size of $C$. parvum progenetic metacercariae, and subsequently egg production, are known to be correlated with intermediate host size (Lagrue and Poulin, 2007). Since P. excavatum is significantly larger than $P$. fluviatilis, $C$. parvum metacercariae adopting progenesis in $P$. excavatum are on average larger and produce more eggs, a result consistent with an effect of host resource availability on $C$. parvum size and egg production.

Alternatively, parasite infections may induce differential mortality rates in the two host species. Interspecific differences in parasite prevalences and abundances between the two amphipod hosts may be explained by a higher parasite-induced mortality in $P$. fluviatilis following infection and/or parasite accumulation. Our results tend to show that differential mortality is unlikely since parasite abundances increased with host size, indicating that both species accumulate parasites as they grow with no apparent increased mortality (Thomas et al. 1995; Rousset et al. 1996). Larger, hence older, individual hosts thus contain higher parasite abundances, because of 
Table 5. General Linear Model testing for the effects of host species (Paracorophium excavatum and Paracalliope fluviatilis), host size (total body length), number of co-infecting parasites (Microphallus sp. and/ or non-progenetic Coitocaecum parvum metacercariae), presence of the nematode Hedruris spinigera and C. parvum size (body length) on the number of eggs produced by progenetic metacercariae in amphipod hosts

(Results shown originate from the model awarded the lowest AIC (Akaike Information Criterion) score. Significant $P$ values are indicated by *)

\begin{tabular}{|c|c|c|c|c|c|}
\hline Factors & Estimate & S.E. & $t$-value & $P$ & Effect size \\
\hline Host species & -0.635 & $0 \cdot 327$ & $-1 \cdot 705$ & $0 \cdot 094$ & $0 \cdot 222$ \\
\hline H. spinigera & $0 \cdot 136$ & $0 \cdot 061$ & $-2 \cdot 225$ & $0.031 *$ & $0 \cdot 285$ \\
\hline Microphallus sp. & $0 \cdot 023$ & $0 \cdot 010$ & $2 \cdot 195$ & $0.033^{*}$ & $0 \cdot 282$ \\
\hline Non-progenetic $C$. parvum & $-0 \cdot 141$ & $0 \cdot 055$ & $-2 \cdot 556$ & $0 \cdot 014 *$ & $0 \cdot 323$ \\
\hline Progenetic C.parvum size & $2 \cdot 424$ & $0 \cdot 469$ & $5 \cdot 169$ & $<0 \cdot 0001 *$ & $0 \cdot 57$ \\
\hline
\end{tabular}

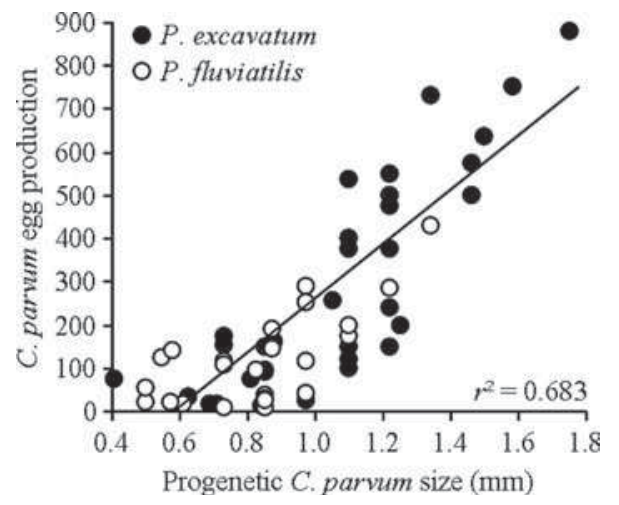

Fig. 3. Relationship between the size of progenetic Coitocaecum parvum metacercariae (body length in $\mathrm{mm}$ ) and egg production in the two amphipod host species, Paracorophium excavatum and Paracalliope fluviatilis.

Line of best fit and coefficient of determination are shown on the figure.

longer time for infections to accumulate (Read and Taylor, 2001). They may also contain older progenetic metacercariae that have had more time for growth and/or egg production.

Several factors tend to indicate that host size rather than host age influences $C$. parvum growth and egg production. First, there is no seasonal variation in C. parvum prevalence, proportion of progenetic metacercariae or size/age distribution in amphipod hosts (Lagrue and Poulin, 2008b). Infection by $C$. parvum is most likely constant over time and host age/size; large/old amphipod hosts should not necessarily contain older metacercariae. Second, growth and egg production can be very rapid in C. parvum; individuals adopting progenesis can quadruple in size in 5 weeks, having produced over 20 eggs by that time and egg production then increasing exponentially with parasite size, unless limited by within-host resources (Lagrue and Poulin, 2007, 2009b). Coitocaecum parvum metacercariae of the same age also show a clear bimodal distribution in size, progenetic individuals being much larger than normal ones while individuals of intermediate sizes are rare (Lagrue and Poulin, 2009b). Size and/or egg production of $C$. parvum metacercariae is thus unlikely to depend solely on the size of individual parasites. Finally, for an equivalent size, female amphipods are older than males but $C$. parvum prevalence, proportion of progenetic metacercariae, as well as egg production, are similar in these hosts (Lagrue and Poulin, 2008a). Amphipod host size, rather than age, likely drives $C$. parvum strategy, size and egg production although host age may eventually have some influence on $C$. parvum strategy (Lagrue and Poulin, 2009b).

Coitocaecum parvum and Microphallus sp. were also found in higher prevalence and abundance in $P$. excavatum than in P. fluviatilis and the nematode $H$. spinigera was found to infect $P$. excavatum only. Intra-host competition is thus more common and probably more intense in P. excavatum. The presence of co-infecting parasites can have variable effects on C. parvum life strategy, size and/or egg production, possibly due to species-specific and abundance related intra-host competition effects. Intra- and interspecific parasite competition can apply to transmission routes and/or host resources (Lagrue and Poulin, 2008a). In P. fluviatilis, the presence of Microphallus sp. did not induce higher progenesis rates but clearly increased egg production in C. parvum. Microphallus sp. manipulates intermediate host behaviour to reach bird definitive hosts while C. parvum must infect a fish host or use progenesis to reproduce (Hansen and Poulin, 2005; Lagrue and Poulin, 2008a). Conflicts over transmission pathways may thus induce progenetic $C$. parvum to produce as many eggs as possible, eventually killing its host, before Microphallus sp. host manipulation succeeds. Our results suggest that this trend is similar and probably exacerbated since Microphallus sp. abundance, and hence host manipulation (Brown et al. 2003), is much higher in P. excavatum. In contrast, co-infection with $H$. spinigera or non-progenetic $C$. parvum, both needing to reach a fish definitive host, seemed to reduce $C$. parvum size and/or egg production. Since there is no conflict over transmission in these situations, host resource limitations most likely induce reductions in size and egg 
production in progenetic individuals (Lagrue and Poulin, 2008a).

Although all parasites probably use similar host resources, results indicate that intra-host competition with $H$. spinigera induces the most drastic reduction in $C$. parvum egg production. This is not surprising since $H$. spinigera larvae are very large compared to progenetic C. parvum (around 8 times larger) and host size (Luque et al. 2007, 2010). Hedruris spinigera likely uses more host resources than the proportionally smaller non-progenetic $C$. parvum or Microphallus sp. metacercariae (around 33\% and 20\% of progenetic C. parvum size, respectively; Lagrue and Poulin, 2008b), thus exerting stronger competition pressure on co-infecting progenetic C.parvum. Coitocaecum parvum's strategy, size and egg production seemed to be influenced by the presence of other parasites in species- and intensity-specific ways. Resource availability in general, be it within-host space or energy, is likely to have strong influences on the size and egg production of progenetic metacercariae.

Overall, the frequency of progenesis did not vary between amphipod host species. However, host size had a small but significant effect on the probability of metacercariae becoming progenetic, regardless of host species. Similarly, host species per se did not strongly influence egg production compared to host size, and thus possibly host age. Disentangling host size and host age effects on C. parvum strategy, growth and/or egg production could be achieved by experimentally infecting amphipod hosts of equivalent age but different size, either males and females of the same species or individuals of the two species used in our study. Alternatively, amphipods of similar size and thus contrasting age could be infected using the same methods (Lagrue and Poulin, 2007).

Within-host resource availability is probably an important factor influencing parasite life strategy, size and egg production and this is largely determined by host size. Since $P$. excavatum hosts are significantly larger than $P$. fluviatilis, apparent host species effects on C.parvum strategy, size and egg production are most likely due to interspecific size differences between intermediate host species. However, further experiments should look at the relative effects of within-host resource (i.e. energy, nutrients) and space (host size) limitations on $C$. parvum metacercariae. This may be tested by experimentally infecting amphipod hosts of similar sizes that are subsequently fed with diets of contrasting nutritive value, or hosts of contrasting sizes fed on an energetically equivalent diet.

In conclusion, results suggest that factors other than host species have more important effects on C. parvum's strategy. These include previously documented factors such as definitive host presence or time since infection, and factors tested herein like intermediate host size or intra-host interactions between co-infecting parasites. Overall, the plasticity offered by facultative progenesis may allow parasites to adjust their developmental strategy in a contextdependent way in response to an array of environmental variables (host size/resources, species-specific intra-host competition, transmission probability) but regardless of host species. Since progenesis acts as a reproductive insurance, allowing individuals to produce at least a few eggs, what maintains progenesis as a facultative strategy is not yet known and would deserve further investigation.

\section{ACKNOWLEDGEMENTS}

This project was funded by an Erasmus Mundus Program 'European Master in Applied Ecology' (EMAE) grant to R.R.D. The authors would also like to thank Richard Sydney Taylor (University of Bristol) for his help during the process and Mathieu Sicard (University of Poitiers) for his administrative assistance. We thank an anonymous reviewer for constructive comments on a previous version of the manuscript.

\section{REFERENCES}

Anurag, A. (2001). Phenotypic plasticity in the interactions and evolution of species. Science 294, 321-326.

Brown, S. P. (1999). Cooperation and conflict in host-manipulating parasites. Proceedings of the Royal Society of London, B 266, 1899-1904. Brown, S. P., De Lorgeril, J., Joly, C. and Thomas, F. (2003). Field evidence for density-dependent effects in the trematode Microphallus papillorobustus in its manipulated host, Gammarus insensibilis. Fournal of Parasitology 89, 668-672.

Coats, J., Nakagawa, S. and Poulin, R. (2010). The consequences of parasitic infections for host behavioural correlations and repeatability. Behaviour 147, 367-382.

Fredensborg, B. L. and Poulin, R. (2005). Larval helminths in intermediate hosts: does competition early in life determine the fitness of adult parasites? International Fournal for Parasitology 35, 1061-1070.

Gower, C. M. and Webster, J. P. (2005). Intraspecific competition and the evolution of virulence in a parasitic trematode. Evolution 59, 544-553.

Grutter, A.S. and Poulin, R. (1998). Intraspecific and interspecific relationships between host size and the abundance of parasitic larval gnathiid isopods on coral reef fishes. Marine Ecology Progress Series 164, 263-271.

Hansen, E. K. and Poulin, R. (2005). Impact of a microphallid trematode on the behaviour and survival of its isopod intermediate host: phylogenetic inheritance? Parasitology Research 97, 242-246.

Holton, A. L. (1984a). A redescription of Coitocaecum parvum Crowcroft, 1945 (Digenea: Allocreadiidae) from crustacean and fish hosts in Canterbury. New Zealand Fournal of Zoology 11, 1-8.

Holton, A. L. (1984b). Progenesis as a mean of abbreviating life histories in two New Zealand trematodes, Coitocaecum parvum Crowfton, 1945 and Stegodexamene anguillae MacFarlane, 1951. Mauri Ora 11, 63-70.

Johnson, K.P., Bush, S.E. and Clayton, D. H. (2005). Correlated evolution of host and parasite body size: tests of Harrison's rule using birds and lice. Evolution 59, 1744-1753.

Lagrue, C. and Poulin, R. (2007). Life cycle abbreviation in the trematode Coitocaecum parvum: can parasites adjust to variable conditions? Fournal of Evolutionary Biology 20, 1189-1195.

Lagrue, C. and Poulin, R. (2008a). Intra- and interspecific competition among helminth parasites: effects on Coitocaecum parvum life history strategy, size and fecundity. International fournal for Parasitology 38, $1435-1444$.

Lagrue, C. and Poulin, R. (2008b). Lack of seasonal variation in the lifehistory strategies of the trematode Coitocaecum parvum: no apparent environmental effect. Parasitology 135, 1243-1251.

Lagrue, C. and Poulin, R. (2009a). Heritability and short-term effects of inbreeding in the progenetic trematode Coitocaecum parvum: is there a need for the definitive host? Parasitology 136, 231-240.

Lagrue, C. and Poulin, R. (2009b). Life cycle abbreviation in trematode parasites and the developmental time hypothesis: is the clock ticking? Fournal of Evolutionary Biology 22, 1727-1738. 
Lagrue, C., Poulin, R. and Keeney, D. B. (2009). Effects of clonality in multiple infections on the life-history strategy of the trematode Coitocaecum parvum in its amphipod intermediate host. Evolution 63, 1417-1426.

Lefèbvre, F. and Poulin, R. (2005). Progenesis in digenean trematodes: a taxonomic and synthetic overview of species reproducing in their second intermediate hosts. Parasitology 130, 587-605.

Luque, J. L., Bannock, L. M., Lagrue, C. and Poulin, R. (2007). Larval Hysterothy-lacium sp. (Nematoda, Anisakidae) and trematode metacercariae from the amphipod Paracorophium excavatum (Corphiidae) in New Zealand. Acta Parasitologica 52, 146-150.

Luque, J.L., Vieira, F. M., Herrmann, K., King, T. M., Poulin, R. and Lagrue, C. (2010). New evidence on a cold case: trophic transmission, distribution and host specificity in Hedruris spinigera (Nematoda: Hedruridae). Folia Parasitologica 57, 223-231.

MacFarlane, W. V. (1939). Life cycle of Coitocaecum anaspidis Hickman, a New Zealand digenetic trematode. Parasitology 31, 172-184.

Parker, G. A., Chubb, J.C., Roberts, G. N., Michaud, M. and Milinski, M. (2003). Optimal growth strategies of larval helminths in their intermediate hosts. Fournal of Evolutionary Biology 16, 47-54.

Paterson, S. and Piertney, S. B. (2011). Frontiers in host-parasite ecology and evolution. Molecular Ecology 20, 869-871.

Poulin, R. (2007). Evolutionary Ecology of Parasites. 2nd Edn, Princeton University Press, Princeton, NJ, USA

Poulin, R. and Cribb, T. H. (2002). Trematode life cycles: short is sweet? Trends in Parasitology 18, 176-183.

Poulin, R., Nichol, K. and Latham, A.D. M. (2003). Host sharing and host manipulation by larval helminths in shore crabs: cooperation or conflict? International Fournal for Parasitology 33, 425-433.
Rauch, G., Kalbe, M. and Reusch, T. B. H. (2005). How a complex life cycle can improve a parasite's sex life. Fournal of Evolutionary Biology 18, 1069-1075.

R Development Core Team (2011). R: A Language and Environment for Statistical Computing. Vienn, Austria. ISBN 3-900051-07-0, URL http://www.R-project.org/.

Read, A. F. and Taylor, L. H. (2001). The ecology of genetically diverse infections. Science 292, 1099-1102.

Rousset, F., Thomas, F., de Meeüs, T. and Renaud, F. (1996). Inference of parasite-induced mortality from distributions of parasite loads. Ecology 77, 2203-2211

Saad-Fares, A. and Combes, C. (1992). Abundance/host size relationship in a fish trematode community. Fournal of Helminthology 66, 187-192.

Schnabel, K. E., Hogg, I. D. and Chapman, M. A. (2000). Population genetic structure of two New Zealand corophiid amphipods and the presence of morphologically cryptic species: implications for the conservation of diversity. New Zealand Fournal of Marine and Freshwater Research 34, 637-644.

Thomas, F., Brown, S. P., Sukhdeo, M. and Renaud, F. (2002a). Understanding parasite strategies: a state-dependent approach? Trends in Parasitology 18, 387-390.

Thomas, F., Fauchier, J. and Lafferty, K. D. (2002b). Conflict of interest between a nematode and a trematode in an amphipod host: test of the "sabotage" hypothesis. Behavioural and Ecological Sociobiology 51, 296-301. Thomas, F., Renaud, F., Rousset, F., Cézilly, F. and de Meeüs, T. (1995). Differential mortality of two closely related host species induced by one parasite. Proceedings of the Zoological Society of London 260, 349-352. Van Valen, L. (1974). Molecular evolution as predicted by natural selection. Fournal of Molecular Evolution 3, 89-101. 